\title{
Elementos para la construcción de un modelo de gestión dirigido a la banca comunal en Ecuador*
}

\section{Elements for the Construction of a Management Model for the Communal Banking in Ecuador}

\author{
Yamile Alexandra Montalvo Alemán** \\ Víctor Julio Jácome Calvache****
}

Recibido: 19 de Julio de 2018

Revisado: 20 de Agosto de 2018

Aprobado: 20 de Septiembre de 2018

* El artículo recoge los resultados de una investigación realizada en Ecuador sobre el tema de banca comunal. Cómo citar este artículo: Montalvo, Y. A., y Jácome, V. J. (2019). Elementos para la construcción de un modelo de gestión dirigido a la banca comunal en Ecuador. Revista CIFE: Lecturas de Economía Social, 20(32), 79-102. doi: https://doi. org/10.15332/22484914.4857

** Docente investigadora del Centro de Economía Pública y Sectores Estratégicos del Instituto de Altos Estudios Nacionales - IAEN, Universidad de Posgrados del Estado de Ecuador. Ingeniera en Finanzas, magíster en Economía Social y Solidaria. Correo electrónico: yamile.montalvo@iaen.edu.ec y yamita.montalvo@hotmail.com

*** Coordinador de la maestría de Investigación en Economía Social y Solidaria, y docente investigador en el IAEN, Ecuador. Dr. (c) en Historia Latinoamericana. Correo electrónico: vicj2c@hotmail.com 


\section{Resumen}

Este artículo presenta aproximaciones para la elaboración de un modelo de gestión dirigido a la banca comunal para el Ecuador. El estudio comparativo de las organizaciones, Banca Comunal A de la ciudad de Latacunga y el Banco Comunitario B de la ciudad de Quito ${ }^{1}$, visibilizó la urgencia de herramientas de gestión apropiadas a sus realidades, considerando que sus prácticas y principios -inclusión, ayuda mutua, solidaridad, autogestión y participación democrática-, difieren de la banca convencional y se enmarcan en las finanzas populares y solidarias. La información cuantitativa-cualitativa, producto del trabajo de campo, permitió comprender las dinámicas internas y las relaciones externas de las organizaciones y, posterior, establecer los elementos básicos del modelo de gestión que se propone en este trabajo.

Palabras clave: finanzas en economías urbanas y rurales, modelo de gestión, economía social, economía de minorías.

Clasificación JEL: R51, M19, B55, J15

\section{Abstract}

This article presents approximations for the elaboration of a management model directed to the communal banking for Ecuador. The comparative study of the organizations, Banca Comunal A from Latacunga City and Banco Comunitario B from Quito city, made visible the urgency of management tools appropriates to their realities, considering that their practices and principles -inclusion, mutual aid, solidarity, self-management and democratic participation-, differ from the conventional banking and are framed in the popular and solidarity finances. The qualitative-quantitative information, product of the fieldwork, allowed to understand the internal dynamics and the external relations of the organizations and, later, to establish the basic elements of the management model proposed in this work.

Keywords: finance in urban and rural economies, management model, social economics, economics of minorities.

Classification JEL: R51, M19, B55, J15

1 A efectos del presente artículo, los nombres de las organizaciones han sido reemplazados para guardar la confidencialidad de la información de estas. Los nombres colocados son: Banca Comunal A, Banco Comunitario B y Cooperativa de Ahorro y Crédito XY. 


\section{Introducción}

En las últimas décadas, el campo de las finanzas populares y solidarias, especialmente en América Latina, ha dado lugar a importantes innovaciones con respecto a las tecnologías financieras utilizadas, tanto en la dimensión de oferta de servicios financieros como bajo la forma de políticas institucionales.

Una de esas innovaciones es la banca comunal, que puede ser concebida como metodología crediticia, y tiene su origen en organizaciones financieras o no financieras. Uno de sus objetivos es atender las necesidades crediticias de una amplia y creciente masa de la población pobre, con la correspondiente rentabilidad financiera para las instituciones que la promueven. En este sentido, su aplicación ha sido considerada como un medio eficiente para alcanzar nichos de mercado tradicionalmente no atendidos, con la posibilidad de brindar a sus clientes servicios adicionales al crédito como la educación y capacitación. Trabajos bajo esta perspectiva han sido desarrollados, entre otros, por Ruth Muñoz (2006), quien ha realizado importantes aportes en cuanto a las modalidades microfinancieras, entre ellas la tecnología grupal y banca comunal; así también, Sevilla (2006) ha descrito con detalle los mecanismos de operación del modelo de banca comunal, a partir de la experiencia de Finca Internacional.

Otra forma de banca comunal es la relacionada con el enfoque comunitario, aquí la población afectada por la profundización de la exclusión económica, social y financiera originan formas de organizaciones autogestionadas, cuyo funcionamiento responde a los intereses de la comunidad a la cual pertenece el banco comunal o comunitario. En la mayoría de los casos son entidades cerradas, que no admiten socios que no sean de su territorio, comunidad o barrio de origen; además, se asocian libremente, administran y gestionan sus propios recursos en beneficio de sus localidades, por lo que su aporte al desarrollo local es relevante en términos económicos, sociales, políticos, ambientales y culturales. Bajo este enfoque tenemos trabajos como el de Ortega (2008), cuya caracterización de las estructuras financieras locales es planteada a partir de la sistematización de proyectos de finanzas populares y migración en Ecuador; también tenemos la obra de Mansell (1995), que revela con amplitud las iniciativas financieras de los sectores populares de México, entre ellas las cajas de ahorro y bancos comunitarios.

Para el presente trabajo se han considerado dos organizaciones de las formas de banca comunal antes indicadas: Banca Comunal A que forma parte de la Cooperativa de Ahorro y Crédito XY y que se enmarca en la banca comunal concebida como metodología crediticia; y el Banco Comunitario B de la ciudad de Quito, que es parte de la concepción de banca comunitaria, como organización autogestionada. Además, este estudio se diferencia de los indicados anteriormente, ya que desborda la caracterización general de estas organizaciones, para identificar aspectos que permiten establecer algunos lineamientos para la construcción de un modelo de gestión para la banca comunal, 
considerando que existen pocas herramientas de gestión acordes a sus realidades, lo que les obliga a utilizar mecanismos formulados por las finanzas convencionales, desvirtuando su sentido social y solidario.

Referente a la estructura, este artículo inicia con la explicación sobre la metodología utilizada en el desarrollo de la investigación, posterior, expone los argumentos teóricos utilizados para la comprensión de los estudios de caso. En un tercer momento, muestra una breve descripción de la banca comunal en Ecuador, para en un cuarto apartado centrarse en los estudios de caso mostrando su contexto histórico, modalidad de funcionamiento, fuentes de fondeo y aporte al desarrollo local desde la perspectiva de la economía solidaria; finalmente, plantea, con base a los estudios de caso, los aspectos a ser considerados para la construcción de un modelo de gestión apropiado para la banca comunal.

\section{Metodología}

Partiendo de la propuesta que una metodología adecuada es aquella que contribuya a "enriquecer y hacer posible la comprensión de la realidad social en sus dimensiones objetivas y subjetivas" (Bonilla y Rodríguez, 2005, p. 77), se consideró que, para un mejor acercamiento a las problemáticas de los actores de la banca comunal, es indispensable integrar las estrategias metodológicas cuantitativas y cualitativas.

Respecto a lo cualitativo, se consideró el método etnográfico (Hammersley y Atkinson, 2009) y la heurística (Pardo, Serrano y Jaramillo, 2006). El primero, sirvió para tener una proximidad directa a los miembros de las organizaciones escogidas: Banca comunal A y Banco Comunitario B. Ambas, seleccionadas con base a su historia, trayectoria e impacto social en sus localidades respectivas, además de su apertura y predisposición para participar en la investigación. Es así que se visitó durante un periodo de doce meses a las dos organizaciones, con el fin de comprender sus comportamientos, aspectos sociales de la organización, mecanismos de integración y vinculación de los socios. Para recopilar esta información se utilizaron tres técnicas: las entrevistas semiestructuradas que se realizó a los directivos; dos grupos focales, uno por cada organización, desarrollados con los socios; y la observación participante, que implicó la participación en la vida diaria de las organizaciones. De esta manera, se obtuvo información sobre las características principales de los casos, desde las voces de sus actores.

La empatía que se construyó con las organizaciones permitió el acceso a información de sus archivos. Así se pudo acceder a estatutos de las organizaciones, reglamentos y manuales de crédito, listados físicos o digitales de socios, actas de asambleas, destino de los créditos, entre otros. La información obtenida fue puesta en contextos más amplios a través de la revisión de bibliografía sobre banca comunal, aquí el método heurístico 
fue útil para la identificación de un corpus de conocimientos sobre la banca comunal, tanto desde la revisión de fuentes primarias como secundarias, que permitieron otorgar un orden a la información, y posteriormente, establecer algunos lineamientos sobre un posible modelo de gestión.

En cambio, desde el enfoque cuantitativo, debido a que este favorece el estudio de las características generales de un objeto de estudio (Ragin, 1994, p. 215), se consideró la aplicación de encuestas como instrumento de recolección y medición de datos, con el fin de evidenciar los procesos de capacitación a los socios en las organizaciones, y también para obtener el nivel o grado de participación democrática existente al interior de estas. En este proceso, el método cuantitativo permitió mostrar la covariación entre dos o más características (variables) presentes en cada una de las organizaciones.

La construcción del cuestionario para la aplicación de la encuesta se realizó utilizando preguntas cerradas, es decir con la posibilidad de elegir una sola respuesta de una serie de opciones enunciadas mediante escalamiento Likert, método desarrollado por Rensis Likert en 1932. Consiste en un conjunto de ítems presentados en forma de afirmaciones o juicios, para medir la reacción del sujeto en tres, cinco o siete categorías (Hernández, Fernández y Baptista, 2010, p. 245).

Las encuestas se efectuaron a una muestra probabilística y representativa de la población de socios de cada una de las organizaciones. El cálculo de la muestra en cada caso fue realizado a través del método de muestreo aleatorio simple, considerando una fracción de muestreo no menor a 1/4. El análisis de la información se realizó considerando la representación de los datos a través de la estadística descriptiva, la cual permitió organizar y resumir los datos mediante las medidas de tendencia central tales como: porcentajes y proporciones; además, fue procesada utilizando como instrumento el sistema SPSS mediante sus aplicaciones de regresión lineal para establecer los elementos determinantes en la construcción de la autogestión de los miembros.

Con lo señalado se realizó un acercamiento al problema de investigación desde la postura que la realidad social "es al mismo tiempo objetiva, subjetiva, compleja y dinámica" (Bonilla y Rodríguez, 2005, p. 106), y la aplicación de una metodología mixta permitió una mejor comprensión e interpretación de dicha realidad.

\section{Gestión y finanzas populares y solidarias: una explicación teórica}

A fin de comprender a las organizaciones de la banca comunal, más allá de su caracterización, sino también evidenciando los pros y contras de su funcionamiento para 
encontrar herramientas que les permitan fortalecerse, se utilizaron categorías teóricas que permitan interpretar sus lógicas. Es por ello que el tema es tratado desde las finanzas populares y solidarias y de gestión de organizaciones. Previamente, es necesario definir el concepto "gestión” para luego ponerlo en diálogo con las categorías señaladas.

La "gestión", en términos generales, ha sido asociada con los procesos de administración de una organización, entendidos como una serie de actividades interdependientes ejecutadas para lograr una producción de bienes o servicios económicos socialmente útiles, con la máxima rentabilidad posible para la empresa u organización (Aktouf, 2003, p. 17). Si bien es un concepto en proceso constante de construcción y consolidación de acuerdo con la dinámica económica en la cual se adscribe, ha sido vinculado con las actividades que expresan lo estrictamente operacional.

Sin embargo, la gestión también puede ser entendida desde el alcance, el propósito y las acciones desarrolladas por las organizaciones para establecer las directrices que las conducen a un estado superior de acuerdo con su identidad, fines y propósitos (López y Mariño, 2010, p. 78); esta postura va más acorde al significado etimológico de gestión, que proviene del verbo latino gerere, que significa conducir, dirigir, e incluso, gobernar. Por ello, la gestión no solo comprende lo operacional (administración), sino la conducción y dirección de la organización (gestión estratégica), lo cual exige el diseño de una estrategia que, al considerar los componentes internos y externos, le permitirá garantizar la permanencia y sostenibilidad en el tiempo de la organización. En este sentido, Romero (1998) menciona que "la gestión no existe en sí misma, es el producto de la interacción de múltiples actores, los cuales acaban determinando un sistema de manejo, de proyección y de visión del cotidiano y del futuro" (citado en López y Mariño, 2010, p. 35).

Ahora bien, el concepto finanzas populares y solidarias difiere de la concepción formal de las finanzas - que las mira desde "la utilización del dinero, su precio, su rendimiento, su protección, transferencia y control, su préstamo y, en general, a todas las actividades que hagan al flujo de ingresos y egresos monetarios a lo largo del tiempo" (Muñoz, 2013, p. 217), ya que visibiliza a los actores involucrados, no busca concentrar recursos financieros en pocos sino democratizarlos, y sobre todo pone las finanzas al servicio de las necesidades de todos. Si bien su ámbito de acción está relacionado con la intermediación financiera (considerado desde las finanzas convencionales, como un potente mecanismo de acumulación de riqueza), sus procesos de gestión necesitan estar enmarcados dentro de una lógica financiera alternativa a la convencional; esto implica una manera diferente de ser y de hacer finanzas, no desde la lógica de la acumulación del capital sino centradas en el bienestar de las comunidades (Ortega, 2008, p. 42). 
Estas finanzas poseen múltiples modalidades financieras compuestas por diversas organizaciones que, salvo ciertas excepciones ${ }^{2}$, tienen como esencia la base social que las conforman, por lo tanto, su gestión debe ser establecida dentro de la lógica, los principios y los valores que la caracterizan. En este sentido, la gestión de estas organizaciones debe buscar la organización racional y eficiente de las actividades de estas, para en definitiva, orientar la dimensión económica de la organización hacia la dimensión social; como lo argumentan Orrego y Arboleda (2011):

$\mathrm{Al}$ direccionamiento estratégico desde la formulación, evaluación, seguimiento y control de planes, proyectos y programas, tendientes a mejorar la calidad de vida de los asociados y, en general, de las comunidades en las cuales prestan sus servicios y ejercen su influencia. (p. 103)

Por consiguiente, los procesos de gestión de las organizaciones de finanzas populares y solidarias suponen, por un lado, el compromiso de sostener, ampliar y legitimar los procesos de participación democrática e igualitaria de los socios; y por otro, garantizar la sostenibilidad económica de la organización mediante el desarrollo de productos y servicios que respondan a las necesidades locales generando a la vez, excedentes provenientes de sus actividades económicas.

En lo que refiere a las modalidades financieras populares y solidarias, Muñoz (2013, pp. 218-220) indica que existen: "el cooperativismo de ahorro y crédito", que da lugar a formas como: banca cooperativa, cooperativas de ahorro y crédito, cajas cooperativas de ahorro y crédito y las secciones de crédito de cooperativas no especializadas; las microfinanzas que operan con tres tipos de tecnologías crediticias: grupos solidarios, banca comunal, y la tecnología individual no convencional; las finanzas éticas; los instrumentos monetarios y financieros como monedas sociales, sistemas locales de intercambio, bancos de horas, círculo de ahorro vecinales, entre otros.

Profundizando en el tema de las microfinanzas y banca comunal -ya que determinamos que Banca Comunal A está enmarcada en esta modalidad financiera como tecnología crediticia-, tenemos que la primera categoría constituye los "servicios financieros dirigidos a unidades socioeconómicas de pequeña escala, que son llevados a cabo a través de una multiplicidad de arreglos institucionales, basados en relaciones de proximidad" (Muñoz, 2013, p. 218), mientras que la banca comunal es una metodología crediticia caracterizada por la conformación de grupos, cuyos miembros gestionan el banco mediante una comisión capacitada para este fin por una agencia promotora; el objetivo es la promoción del ahorro y la concesión de préstamos a sus miembros, financiados por la agencia promotora o por la cuenta interna del banco (Muñoz, 2013, p. 219).

2 Actualmente se critica mucho al sector cooperativo de ahorro y crédito, que se está desviando de los principios cooperativos como producto del cambio de su objetivo: ya no lo social sino el lucro, al punto que no buscan socios sino clientes, no apoyan la producción sino el consumo, etc. 
Por el lado de la banca comunitaria (que es una arista de la banca comunal), de la cual es parte el Banco Comunitario B, se tiene que su conformación está dada por personas con vínculos y necesidades comunes que se han asociado libremente en respuesta a la exclusión financiera, económica y social. Quienes son miembros de la banca comunitaria operan bajo principios solidarios tales como la libre asociatividad, la autogestión, la democracia participativa y la ayuda mutua, a través de los cuales han desarrollado mecanismos particulares de recuperación y administración de recursos financieros propios, para alcanzar beneficios comunes dificiles de conseguir en forma individual. Para Ortega (2008), uno de los elementos fundamentales sobre los cuales se construye y sostiene la banca comunitaria es el capital social, que consiste en las relaciones de afinidad y confianza entre los miembros de la organización. Así también, el autor señala que otro elemento importante de estas organizaciones está relacionado con la labor que desarrollan en favor de la comunidad o territorio al cual pertenecen. Esto significa entender la intermediación financiera como una herramienta para el desarrollo local y no como un mecanismo de acumulación de riqueza.

Desde la perspectiva del desarrollo local, la banca comunal no está orientada solo a la entrega de recursos económicos, aun cuando con ello se apoyan prioritariamente iniciativas productivas comunitarias. En esta dinámica se construyen espacios y elementos de enlace de los aspectos sociales, culturales, ambientales, económicos e institucionales de sus territorios, pues estas organizaciones han ido creciendo con la comunidad y con el entorno (favorable o desfavorable), lo cual se constituye a su vez en una de sus principales fortalezas que le permite dar soluciones concretas a los problemas específicos de cada localidad usando los recursos existentes en cada territorio.

En relación con la gestión de recursos, si bien estas organizaciones surgen mediante su autogestión, en importante medida ellos podrían resultar no ser suficientes para cubrir las demandas económicas locales, o peor aún, la escasez de recursos podría eventualmente poner en riesgo la sostenibilidad de la organización; por lo que muchas organizaciones buscan integrarse en redes solidarias de cooperación como una alternativa para generar efectos de escala con visión de sistema; lo cual, como señala Hubenthal (2001), "requiere de un sentido de solidaridad muy pronunciado a nivel de base y de instituciones de segundo grado fundamentalmente subsidiarias" (citado en Ortega, 2008, p. 101).

Ante lo indicado, la identificación de procesos de gestión apropiados para la banca comunal cobra importancia desde el sentido de sostenibilidad a largo plazo; consecuentemente, la aplicación de procesos de gestión que contemplen la lógica y objetivos solidarios de las entidades garantiza en importante medida su sostenibilidad y permanencia en el tiempo. Al respecto, Vuotto y Fardelli (2012) señalan que el potencial de estas organizaciones requiere de un modelo de gestión que considere las implicaciones de su misión económica y social, el papel de sus miembros o asociados, así como las prácticas que favorecen su papel en la democratización de la economía. 
Con el fin de establecer algunos elementos para ese modelo de gestión se analizaron los casos Banca comunal A y Banco Comunitario B, cuyos resultados se presentan a continuación.

\section{Análisis de los casos}

Explicado el marco teórico que orienta este trabajo, y antes de adentrarnos a los casos específicos, es necesario presentar una visión general de la banca comunal en el Ecuador.

La Constitución de la República del Ecuador del 2008 en su artículo 311 reconoció al sector financiero popular y solidario señalando que está conformado por las cooperativas de ahorro y crédito, entidades asociativas o solidarias, cajas y bancos comunales, cajas de ahorro; así, visibilizó la existencia de una pluralidad tanto de sectores financieros (público, privado y popular y solidario) como de formas de organización financiera popular y solidaria.

Es importante aclarar que estas organizaciones no tienen su origen con el reconocimiento constitucional, sino, antecede al siglo XX. El historiador Wilson Miño (2013, pp. 24-26) señala que estas formas asociativas tienen una influencia europea, y empezaron a formarse ante la ausencia del poder privado y público en cuanto al apoyo a los trabajadores en circunstancias de alta vulnerabilidad y mortandad por el azote de enfermedades y epidemias, los accidentes laborales, la muerte y otros gastos imprevistos. Generalmente, estas organizaciones se encontraban adscritas o vinculadas a organizaciones sindicales y artesanales que aparecieron en la época.

En el año 2012 se expidió la Ley Orgánica de Economía Popular y Solidaria y del Sector Financiero Popular y Solidario, que estableció que las organizaciones deben obtener su personería jurídica en la Superintendencia de Economía Popular y Solidaria (2015), empero, no fue hasta enero de 2018 que esta entidad estableció los requisitos para la constitución y catastro de las cajas y bancos comunales y cajas de ahorro del país. Con la promulgación del Código Orgánico Monetario y Financiero del 2014 se estableció que las entidades asociativas o solidarias, cajas y bancos comunales y cajas de ahorro "se forman por voluntad de sus socios, tendrán su propia estructura de gobierno, administración, representación, auto control social y rendición de cuentas", y estableció que su capital estará conformado por aportes económicos de sus socios en calidad de ahorros, y que podrán opcionalmente adoptar personería jurídica, lo cual es requisito indispensable para el acceso a financiamiento, especialmente por parte de entidades públicas (Artículo 458).

De esta manera, el catastro de estas entidades financieras, postergado por periodos inexplicables, ha dificultado el conocimiento, al menos aproximado, del número real de 
organizaciones que se encuentran operando en el país. Por ahora, y de acuerdo con el informe de rendición de cuentas 2014 de la Superintendencia de Economía Popular y solidaria (SEPS), se estima que en Ecuador estarían operando alrededor de 12.000 cajas y bancos comunales.

A pesar de la normativa vigente, que es producto de un proceso arduo de muchos años de organización y trabajo de los actores, la banca comunal debe enfrentar, por una parte, el desafío de desempeñarse "careciendo de un instrumental conceptual y analítico propio que las oriente en sus procesos de toma de decisiones, por lo cual, recurren a menudo a aquellas herramientas de análisis proporcionadas por una ciencia económica convencional" (Razeto, 2010, p. 51) que las desvirtúa y, por otra parte, una institucionalidad que ejerce más su labor de control y supervisión, mas no de fomento. No obstante, esta condición injusta y desigual que ha vivido la banca comunal no ha sido una condición limitante (no solo en Ecuador sino en los países latinoamericanos), al contrario, los actores han creado estrategias que les permiten seguir existiendo.

Así arribamos a los casos de estudio, que son parte de esas iniciativas impulsadas desde la sociedad civil: la Banca Comunal A de la Provincia de Cotopaxi y el Banco Comunitario B de Quito. A continuación, se analiza cada caso a través de tres aspectos: la modalidad de funcionamiento y operación, los mecanismos de vinculación social de los miembros, y finalmente las fuentes y mecanismos de fondeo.

\subsection{Banca Comunal A}

La mencionada organización se constituyó legalmente como una organización sin fines de lucro en agosto de 2006. Su creación fue impulsada por la Cooperativa de Ahorro y Crédito XY quien desde el año 2002, con el apoyo del Consejo Mundial de Cooperativas de Ahorro y Crédito (WOCCU), ejecutó la metodología crediticia de banca comunal como una estrategia microfinanciera para llegar a grupos menos favorecidos, como mujeres cabezas de hogar y microempresarias residentes en zonas de difícil acceso. Con dicho apoyo, la Cooperativa XY proveía los fondos para los créditos, mientras que WOCGU asumía los gastos administrativos de la metodología. El apoyo de WOCGU finalizó en el año 2006. WOCGU fue constituido el 1 de enero de 1971 y tiene sede en Madison, Wisconsin. Es la principal asociación gremial internacional y agencia para el desarrollo de las cooperativas de ahorro y crédito. Su misión es ayudar a sus miembros y posibles miembros a organizar, expandir, mejorar e integrar las cooperativas de ahorro y crédito e instituciones relacionadas como instrumentos eficaces para el desarrollo económico y social de la población (para más información consultar www.woccu.org).

A partir de ese año, la Cooperativa XY impulsó la creación de la Banca Comunal A con la idea de establecer una organización autosustentable, sin fines de lucro, que continúe con la administración de la tecnología crediticia de banca comunal ya implementada. 
La tecnología crediticia aplicada por la Banca Comunal A responde al diseño original de WOCGU y a su Programa Crédito con Educación Rural CREER, que es un producto basado en la metodología de microfinanzas grupales y consta de tres componentes: 1) crédito: para emprender una actividad económica que permita a las participantes generar ingresos adicionales para el hogar; 2) ahorro: para crear una cultura que permita a los participantes disponer de dinero en efectivo para solventar situaciones previstas o imprevistas, evitando así el endeudamiento en tales situaciones; 3) educación: para brindar información que les permita mejorar la vida familiar y del negocio.

Esta metodología consiste en la conformación de bancos comunales de entre 7 a 30 mujeres, para facilitar el acceso a servicios financieros diseñados especialmente para aquellas de bajos ingresos y económicamente activas, que sean capaces de participar exitosamente en emprendimientos individuales. Así, organizan los bancos comunales en comunidades pequeñas, especialmente rurales, donde hay poco o ningún servicio financiero disponible. El banco comunal seleccionado solicita préstamos a la Cooperativa XY, para luego dividirse equitativamente entre cada una de las socias; al ser grupos pequeños, se garantiza que todas se conozcan, de tal forma que el grupo garantiza el pago de cada una de las integrantes.

La encuesta aplicada a este banco evidenció que las socias orientan el crédito para financiar actividades productivas: el $86 \%$ destinaron el crédito para el financiamiento de actividades productivas, frente al $14 \%$ que lo usaron para actividades de interés particular como la educación y emergencias de salud.

En relación con los montos de crédito, ellos oscilan entre 500 USD por socia, hasta un máximo de 2.000 USD por socia, otorgados en 6 ciclos de 16 semanas cada uno. La entrega de los créditos se realiza con un encaje del $5 \%$ del monto de crédito solicitado.

Respecto al ahorro, este se realiza bajo dos modalidades: obligatoria y voluntaria, prevaleciendo la primera, especialmente, para las personas que mantienen créditos. De esta forma, el pago del préstamo junto con el ahorro obligatorio más el ahorro voluntario (si lo hubiera), son recaudados y registrados en las reuniones semanales, quincenales o mensuales del grupo.

Por su parte, la educación en el Programa CREER tiene tres áreas temáticas: autoestima, salud y negocios. Las sesiones educativas se realizan en alrededor de 20 minutos durante las reuniones para pago de préstamos y entrega de ahorros. Con ello se pretende que las beneficiarias puedan tener no solo acceso a recursos económicos para incrementar sus activos productivos, sino que también puedan administrarlos y utilizarlos productivamente, al tiempo que mejoran su autoconfianza y desarrollan habilidades en el manejo de micronegocios. 
Un aspecto importante por resaltar dentro de la metodología es el denominado empoderamiento social que se pretende desarrollar en las mujeres participantes como resultado del ejercicio de funciones de responsabilidad al interior del grupo (presidencia, tesorería). Está práctica permite que ellas se responsabilicen de sus decisiones y establezcan sus propias reglas de participación, junto con las sanciones respectivas en caso de incumplimiento, con lo cual se estaría motivando la autogestión al interior de los bancos comunitarios. El trabajo de campo mostró que la autogestión y empoderamiento que se está favoreciendo a través de esta metodología, se relaciona con la organización y administración de los bancos comunales, ello está circunscrito al espacio de los grupos y no se aplican en espacios de decisión administrativa y técnica de Banca comunal A o la Cooperativa XY, por ejemplo, cambios en la metodología, desarrollo de nuevos productos o plazos, fijación de tasas de interés, comisiones, etc.

Es claro que la intención de la organización en estudio es propiciar la autogestión enfocada a las mentalidades y los comportamientos de las personas. Esto se evidencia con las respuestas del $76 \%$ de las mujeres encuestadas que manifestaron que no dejarían el grupo solidario aún si tuvieran acceso a un crédito individual en otra entidad financiera; así también, la fidelidad de las socias hacia la metodología de la Banca Comunal A tiene relación directa con la capacitación recibida principalmente en temas de manejo de emprendimientos y salud que las socias señalaron haber recibido.

En relación con las fuentes y mecanismos de fondeo, es importante señalar que la Banca Comunal A no maneja capital financiero para la colocación de créditos; la cartera es financiada en su totalidad por la Cooperativa XY con la tasa de interés vigente en el mercado para microcréditos (19.5\%). Por su parte, la Banca Comunal A se encarga de la colocación, administración y recuperación de la cartera. Por lo tanto, la organización no realiza actividades de intermediación financiera que consideran como una de las principales fuentes de fondeo, la captación de recursos mediante el ahorro, para posteriormente entregarlos como créditos. Esta organización se autosustenta con sus actividades de colocación, administración y recuperación de cartera, lo cual es posible a través del cobro de una comisión por servicios del $4.5 \%$ sobre los créditos otorgados a los socios.

Esta comisión está incluida dentro la recuperación normal de cartera, junto con la tasa de interés cobrada por la Cooperativa de Ahorro y Crédito XY: efectiva anual de 20.5 $\%$, y adicionalmente el valor correspondiente por seguros de salud y de vida: 42.00 USD como valor fijo anual (año 2016). Así también, es relevante señalar que a diciembre de 2015 la cartera vencida de la Banca Comunal A representaba el $2.37 \%$, lo cual es un índice aceptable de acuerdo por lo señalado por el BID, con base a su estudio de las cuatro mejores instituciones de banca comunal en América Latina. En él se señala que los índices de morosidad de esta metodología son impresionantemente bajos, siempre son menos de $5 \%$ (BID / Westley, 2003, p. 25). 


\subsection{Banco Comunitario B}

$\mathrm{Al}$ igual que otros barrios urbano-marginales de Quito, Atucucho, ubicado al noroccidente de la ciudad, se conformó de manera ilegal durante la década de los 80 , lo cual durante muchos años motivó la falta de aprovisionamiento de servicios básicos para el sector y evidentemente, la inseguridad jurídica del suelo de los posesionarios. Frente a estas necesidades, y en medio de situaciones de conflicto interno y externo, surge entre otras organizaciones barriales el Comité Promejoras, el cual promovió la creación del Banco Comunitario B para solventar las necesidades de financiamiento de la población, especialmente, para conseguir la legalización de sus tierras. La creación del Banco Comunitario B se concretó en noviembre de 2012 como una sociedad de hecho, mas no de derecho, puesto que al momento de su institución no se disponía de normativa vigente para el registro de este tipo de organizaciones.

El Banco B orienta sus servicios y productos financieros hacia la población de Atucucho, que cuenta con tres grandes categorías de actividades económicas: a) comerciantes: ventas ambulantes y minoristas; b) asalariados del sector público y privado; c) conductores de taxi. Opera con microcréditos, los cuales pueden ser ordinarios o emergentes, siendo la diferencia principal entre ambos los plazos del crédito, aunque en la práctica la totalidad de la cartera de la organización se encuentra dentro de la categoría de microcréditos ordinarios. Dentro de estos, el plazo de cancelación se fija de acuerdo con los montos otorgados, que van de 100 USD a 3.000 USD con plazo máximo de 18 meses.

Si bien uno de los objetivos fundamentales del Banco Comunitario B es impulsar las actividades productivas del sector, la encuesta realizada muestra que el $71 \%$ de los créditos entregados fueron destinados a intereses particulares antes que a inversiones para actividades productivas. De hecho, el destino principal de los créditos es la vivienda, lo cual tiene relación con el origen de la organización.

Figura 1. Finalidad de los créditos otorgados por el Banco Comunitario B

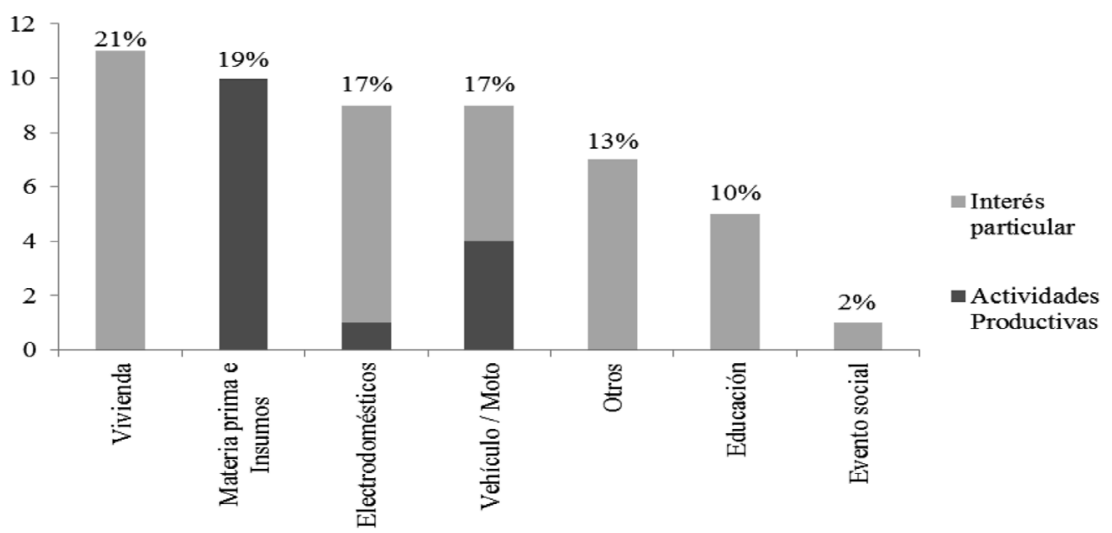

Fuente. Elaboración propia 
El requisito principal para adherirse a la organización es pertenecer a la comunidad o bien ser propietarios de viviendas localizadas en el sector de incidencia. Sin embargo, los nuevos socios, quienes reciben la categoría de comunitarios, en ningún caso pueden alcanzar la condición de socios fundadores que, entre otros beneficios, otorga la posibilidad de participar activamente en las decisiones del banco. En consecuencia, la participación en asamblea general de socios como máximo organismo de decisión, es privilegio exclusivo de los socios fundadores, quienes representan el $6.5 \%$ del total de socios de la organización. Los 28 socios fundadores son, por lo tanto, quienes conforman todos los estamentos administrativos de la organización: Asamblea General, Directorio, Coordinación de Veeduría, Coordinación de Educación y Formación y Coordinación de vinculación con la comunidad.

Acorde con lo anterior, el $99 \%$ de los socios comunitarios jamás ha participado en alguna actividad del Banco B, sea esta una asamblea, reunión para rendición de cuentas o reunión social. Como resultado de ello, el capital social de la organización, es decir, las relaciones sociales de confianza interna resultan ser inexistente, porque dichas relaciones dependen en mayor escala del grado de participación que cada uno de los socios tenga al interior de la organización.

Rosanvallon (1979, p. 88) explica que los procesos de participación constituyen un método de despegue político y económico donde las organizaciones son una especie de escuelas prácticas que favorecen la constitución de nuevos dirigentes administrativos y técnicos. En el Banco Comunitario B es claro que dicho ejercicio no ha sido democratizado y, por lo tanto, la búsqueda de mecanismos que promuevan la democracia participativa ampliada, antes que la democracia representativa, es una tarea pendiente de la organización. Según el análisis realizado esto es posible hacerlo desde espacios de capacitación idóneos, creados y diseñados para el cumplimiento de este objetivo.

Ahora bien, el estudio evidenció que la organización no incluye dentro de sus servicios asistencia técnica y capacitación a sus socios comunitarios, contrario con los fundadores que reciben capacitación en varios temas; sin embargo, el $96 \%$ de los socios encuestados manifestaron tener interés en recibir capacitación, especialmente, en el manejo de emprendimientos individuales o asociativos, quedando clara su necesidad de fortalecimiento técnico de las actividades productivas, junto con la priorización del financiamiento hacia estas actividades.

También es evidente la falta de conocimiento técnico de la gestión integral de este tipo de organizaciones por parte de los socios fundadores. Este es el elemento clave que explica la ausencia de actividades tendientes a fortalecer el capital social de la organización y, en consecuencia, motivar el desarrollo socioeconómico del sector. Por otra parte, la autogestión de recursos a través del mecanismo de aportes patrimoniales se constituye en el principal mecanismo de fondeo permanente del Banco Comunitario B, especialmente 
para el grupo de socios fundadores, no así para el resto de los socios quienes, por vía coercitiva, en la realización de los pagos de créditos, aportan con valores mínimos a este propósito. Esta acción determina, sin duda, la desigualdad entre los socios de uno y otro grupo, lo cual estimula el sentido de pertenencia de la organización por parte del grupo minoritario de socios fundadores.

En relación con la recuperación de los créditos entregados, tiene un indicador de cartera vencida equivalente al $29.3 \%$, lo cual excede por mucho las cifras aceptables de morosidad para este tipo de organizaciones (de acuerdo a la herramienta de evaluación de la Corporación Nacional de Finanzas Populares y Solidarias en Ecuador, el indicador de cartera vencida del año 2016, no excede el $5 \%$ sobre el total de cartera de las instituciones de FPS); ello tiene impacto de grandes proporciones en los resultados financieros de esta, pudiendo en el corto y mediano plazo afectar seriamente la sostenibilidad económica de la organización. Las cifras de morosidad confirmaron que por ser una organización desprovista de vínculos sociales estrechos con la totalidad de los socios (beneficiarios en su mayor parte de los créditos), el correspondiente riesgo de recuperación de cartera se amplía, motivando el retraso o falta de pagos de los recursos entregados. Ello constituye sin duda, uno de los efectos más importantes de la ausencia del capital social de la organización, porque como señala Ortega (2008, p. 52), la identidad y el sentido de pertenencia a una organización, motiva la fidelidad de las personas.

\section{Elementos para la construcción de un modelo de gestión para la banca comunal a partir de los casos analizados}

Con base en las características particulares de las organizaciones analizadas, se han identificado tres dimensiones que constituyen los factores a ser valorados en la construcción de un modelo de gestión tendiente a potenciar el alcance y efectividad de los bancos comunales en el Ecuador, estas son: capital social, orientación hacia el desarrollo local e integración; no obstante, se encuentran supeditadas a los principios que enmarcan las prácticas de las finanzas populares y solidarias, que ya se indicaron en los apartados anteriores; por otra parte, estas dimensiones no se concentran solamente en la esfera económica-financiera, como lo hacen las finanzas convencionales, sino, se encuentra imbricada a las esferas cultural, política, social y ambiental y, sobre todo, están dirigidas a garantizar la reproducción ampliada de la vida.

En este sentido, una propuesta preliminar de modelo de gestión (figura 2) que esté acorde al contexto de la banca comunal debería tener como principio y fin el ser 
humano, a quien debe dirigirse toda acción, no el capital. Las dimensiones indicadas y, en general, todo el modelo de gestión, deben sostenerse sobre los principios y valores de finanzas populares y solidarias, y garantizar la sostenibilidad integral de las organizaciones.

Figura 2. Esquema de la propuesta de modelo de gestión para la banca comunal

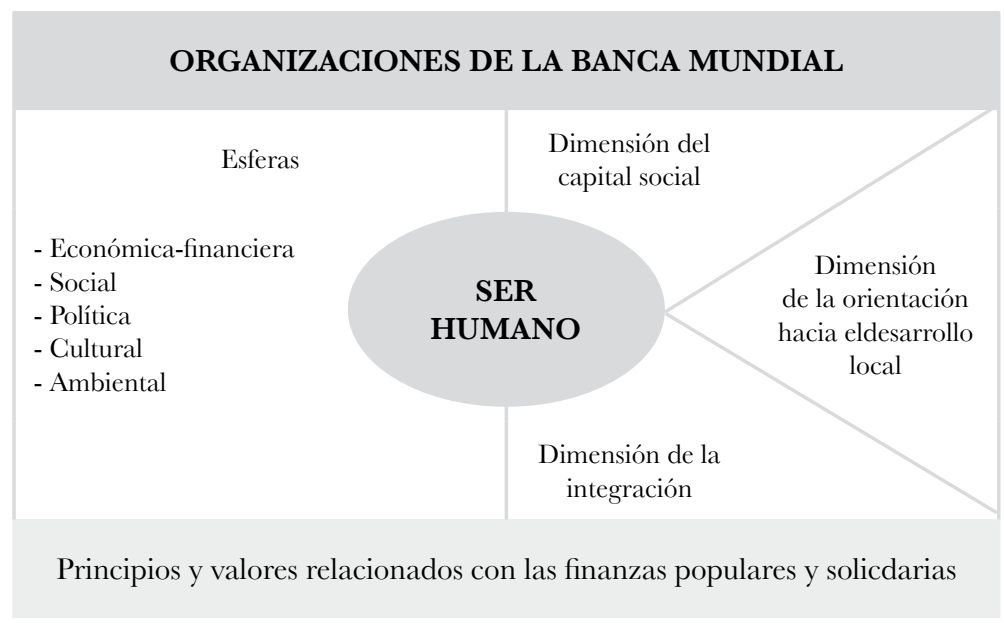

Fuente. Elaboración propia

Como tal, la filosofía de las finanzas populares y solidarias donde se explicaron los principios y su carácter integral respecto a mirar todas las esferas ha sido explicada tanto en el marco teórico como en la descripción de los casos. Es por ello, que a continuación se analizan las dimensiones:

\subsection{Capital social}

El capital social de una organización está constituido por las relaciones sociales que "combinan actitudes de confianza con conductas de reciprocidad y cooperación" (Durston, 2003, p. 147). Este elemento de confianza no solo que se expresa en relaciones fraternales y solidarias, sino también en la entrega del control de bienes personales, tales como los financieros; por lo tanto, se puede decir que, en general, la dinámica de las organizaciones financieras populares y solidarias está determinada por el vínculo social entretejido al interior de estas y el impacto que dichas relaciones provocan en su comunidad cercana.

Con base en la confianza mutua, las organizaciones superan las barreras del individualismo para dar paso al interés colectivo, que forma parte de sus identidades y contribuye a asumir en conjunto el riesgo (Durston, 2003, p. 147). Este sentido de identidad se evidencia en los casos analizados, por ejemplo, en el Banco Comunitario 
B surge como una expresión de participación colectiva en la creación de la entidad y también, en el depósito de los ahorros para que sean administrados por sus propios vecinos; a pesar de que su limitante es que el sentido de identidad se circunscribe al grupo de los socios fundadores. De allí que el capital social de esta organización no se encuentre plenamente expresado al interior de esta, y ella deba recurrir a mecanismos convencionales de minimización del riesgo, tales como la información de central de riesgos o garantías reales.

En este sentido, es importante trabajar en esta dimensión, considerando que el capital social no es algo natural, no surge espontáneamente, es más bien el resultado de una construcción, que "supone importantes inversiones materiales, simbólicas y de esfuerzos que implican otros gastos" (Bourdieu, 1990 citado en Hintze, 2004, p. 6).

Por el contrario, en la Banca Comunal A esta dimensión se presenta más fuerte, y uno de los mecanismos utilizados para alcanzarlo ha sido la capacitación que ha contribuido al fortalecimiento de los vínculos sociales al interior de los grupos, y se manifiesta en una relación de largo plazo con la institución. Esta capacitación, empero, no se centra solo en la esfera económica, sino que ha desarrollo procesos de autogestión que miran lo social, político y técnico (Peixoto, 2004, p. 46).

Así, lo económico trata de procesos espontáneos de autogestión de recursos, lo técnico está relacionada con el desarrollo y formación de capacidades, mientras que lo social y político tiene relación con el ejercicio del poder (participación democrática) y las decisiones de la organización. Con esto se impulsa la autogestión desde su acepción humanista, es decir, buscando la transformación del ser en el sentido de fomentar relaciones sociales abiertas y fraternales, capaces de cambiar realidades individuales, pero también de la comunidad.

Sin embargo, en estos procesos de autogestión, la participación democrática es uno de los principios importantes, que hace de las organizaciones de las finanzas populares y solidarias diferentes a las convencionales, ya que es determinante la internalización de procesos ampliados de participación democrática, pero no como un requisito para la concesión de créditos, sino como un proceso fundamental del ejercicio de un derecho de todos los socios, lo cual, constituye la base del capital social de la organización.

La banca comunal, esencialmente, debe estar constituida por un capital social firmemente establecido a partir, por lo menos, de tres esferas: económica, sociopolítica y técnica. Ello implica, como se ha demostrado, la construcción de vínculos sociales estables y sólidos basados en la confianza mutua, e instituidos desde la combinación de dos elementos: por un lado, la capacitación y formación de los individuos y, por otro lado, la participación democrática ampliada a todos los miembros de la organización. 


\subsection{Orientación hacia el desarrollo local}

La temática del desarrollo local es sin duda una de las más controvertidas teorías desde el enfoque económico y social. Para este caso, se aborda el tema desde la comprensión del alcance de las actividades microfinancieras en los territorios de incidencia. En ese sentido, el desarrollo local se entiende desde una perspectiva que reconoce los recursos, capacidades y aspiraciones de individuos que, estratégicamente organizados y reconocidos, pueden transformar favorablemente su realidad socioeconómica. La noción de local no hace referencia a algo pequeño o insignificante, tiene que ver más bien con una población que comparte condiciones socioeconómicas comunes, comparten una historia de asentamiento, aunque a veces la desconocen y comparten una vida cotidiana más o menos conflictiva o solidaria (Coraggio, 2013).

El enfoque de desarrollo local a considerar para la construcción de un modelo de gestión para la banca comunal está relacionado con el aprovechamiento, ampliación y fortalecimiento de las capacidades locales endógenas en beneficio de la propia comunidad. Ello implica: a) el fomento e impulso de las actividades productivas, b) la creación de espacios de integración de las personas en condiciones de igualdad, c) la construcción de nuevos sujetos sociales, conscientes de su valor individual e identidad histórica, que les permite ejercer con convicción, su legítimo derecho de participación directa, así como sus cualidades de liderazgo en espacios creados para el efecto.

El desarrollo local, así conceptualizado, expone tres aspectos que deberían orientar los procesos de gestión de las organizaciones de las finanzas populares y solidarias y, particularmente, de los bancos y cajas comunales.

\subsubsection{Primer aspecto}

El fomento e impulso de las actividades productivas requiere evidentemente la priorización de su financiamiento; ello requiere de la innovación permanente de productos crediticios que respondan a las necesidades y demandas de la comunidad. Esto implica la incorporación de mecanismos de garantías y repago acordes a la lógica de las actividades productivas del territorio o comunidad. En este sentido, es necesario rebasar las condiciones crediticias convencionales, puesto que han mostrado ser limitadas e inapropiadas para el financiamiento de las organizaciones comunitarias o asociativas, porque "introducir con espíritu capitalista financiamientos a una empresa solidaria, la tenderá a convertir en capitalista, generando distorsiones que la alejarán de su genuina y eficiente racionalidad" (Razeto, 2001, p. 6).

\subsubsection{Segundo aspecto}

La integración de las personas en condiciones de igualdad es efectivamente condición imprescindible en procesos de inclusión social. El involucramiento de todos los 
miembros de la organización en las actividades de esta, sean de tipo administrativo o social, busca ante todo el establecimiento y ampliación de vínculos sociales fraternos y solidarios, que como se mencionó anteriormente, son la esencia del denominado capital social de estas organizaciones.

\subsubsection{Tercer aspecto}

La construcción de nuevos sujetos sociales conlleva a la noción de la autogestión. No se trata simplemente de capacitar individuos para que desarrollen sus capacidades en función de sus intereses particulares, se trata de formar individuos con intereses colectivos, plenamente identificados con los objetivos de la organización y comunidad a la que pertenecen. Para ello, los bancos y cajas comunales, enfocados casi exclusivamente en la colocación de recursos a través de créditos, deberán canalizar prioritariamente sus esfuerzos y recursos hacia la capacitación y formación de sus miembros, porque como explica Muñoz (2006, p. 61), el crédito, por sí mismo, no puede crear oportunidades productivas. No puede ser un sustituto de otros motores del desarrollo tales como la formación de capital humano. El crédito solo puede complementar otros ingredientes del desarrollo local.

La capacitación y formación de los miembros es evidentemente un aspecto fundamental del quehacer de estas organizaciones. El estudio realizado demostró que es el elemento de mayor incidencia en la ampliación de vínculos sociales, pero también lo es en la construcción de nuevos ciudadanos autogestionarios y empoderados.

\subsection{Integración}

La integración de las organizaciones de la EPS, en general, es una condición indispensable para avanzar hacia la consolidación sistémica del sector. Lo propio ocurre con el subsector de las finanzas populares y solidarias, donde la disponibilidad de los recursos determina el alcance y capacidad de incidencia de las organizaciones en términos económicos.

Laville (1993) señala que la combinación de recursos provenientes de distintas fuentes constituye una estrategia de financiamiento que garantiza la sostenibilidad financiera de las organizaciones de la economía solidaria. Si bien el autor se refiere a la combinación de los recursos provenientes de "la venta de las prestaciones, la utilización negociada de los financiamientos que provienen de la redistribución (Estado, municipios) y la elaboración de complementariedades entre asalariados y voluntarios" (Laville, 1993, p. 33), la noción de hibridación de recursos no designa exclusivamente la utilización de estos tres tipos de recursos para el desarrollo de las actividades, sino un nuevo equilibrio entre varios tipos de actores, y en particular el establecimiento de nuevas relaciones entre sociedad civil y Estado. Lo expuesto manifiesta la necesidad de combinar los recursos 
propios de la organización, con los aportes que el Estado pudiera y debiera brindar a esta, pero también desde la construcción de redes de integración entre organizaciones afines al sector.

En el marco de los casos analizados, lo indicado se evidencia en el respaldo y apoyo de instituciones ampliamente experimentadas en el ramo y con sólido capital económico, como es el caso de la Cooperativa XY, que contribuye de gran manera a la consolidación y crecimiento de la Banca Comunal A. Por otro lado, el caso del Banco Comunitario B muestra que, si bien la autogestión de recursos ha impulsado el crecimiento de la institución de manera moderada, este no ha podido ampliarse y canalizarse hacia el desarrollo de actividades productivas de mayor alcance, debido precisamente a la ausencia de apoyo por parte de una entidad mayor.

Aquí, el apoyo estatal es condición imperante en las organizaciones de finanzas populares y solidarias; sin embargo, mientras se consolida la voluntad política de facilitar el acceso a recursos desde el Estado, la ayuda externa podría ser más viable y eficiente desde las entidades de la sociedad civil. No se trata de la adopción de modelos de tecnología crediticia, se trata de promover la integración de organizaciones dispuestas a complementarse en función de la consecución de un objetivo común: la consolidación y fortalecimiento del sistema financiero popular y solidario.

Desde esta perspectiva, es necesario considerar lo que señala Ortega (2008), para quien las pequeñas organizaciones de intermediación financiera deben transitar desde su situación inicial para "avanzar hacia una estructuración de servicios que implica nuevas capacidades y el establecimiento de conexiones con otro tipo de actores en busca de relaciones recíprocas, de cooperación o de apoyos institucionales específicos” (p. 51).

\section{Conclusión}

Los casos analizados sobre la banca comunal en Ecuador permitieron identificar sus mecanismos y prácticas de inclusión financiera, económica y social, y de esta manera establecer aspectos comunes y fundamentales que pueden permitir la construcción de un modelo de gestión acorde a sus realidades.

Es así que se establece como una de las características esenciales de estas organizaciones a la autogestión, que es un derecho directo de los miembros para intervenir y participar activamente en todo lo concerniente al funcionamiento de la organización, sin embargo, no hay que confundirse con la gestión democrática, asumida como un sistema de participación dentro de una metodología específica. En este sentido, encontramos que mientras la Banca Comunal A impulsa una gestión inclusiva orientada hacia la 
autogestión humanista de sus socias, el Banco Comunitario B no tiende a constituir acciones que permitan la formación de sujetos autogestionarios

El capital social es otro elemento para considerar, especialmente, para garantizar la sostenibilidad de las organizaciones. Este constituye un factor que se construye y desarrolla con base al ejercicio de la participación democrática y la programación intensiva de procesos de capacitación; ello constituye además uno de los aspectos que configuran el desarrollo local en el ámbito sociopolítico de las organizaciones de las finanzas populares y solidarias.

Un tercer elemento por destacar es el alcance económico y territorial de las organizaciones. En este caso un factor esencial que determina no solo su alcance operativo e impacto socioeconómico, sino también su sostenibilidad en el tiempo, son los respaldos y apoyos que otras instituciones sólidas, tanto públicas como privadas, puedan brindar a las experiencias. La experiencia de la Banca comunal A, por ejemplo, muestra que la ampliación de su alcance económico y territorial está relacionada con el apoyo y respaldo de dos entidades considerablemente posicionadas en el ámbito financiero nacional e internacional, como son la Cooperativa XY y WOGGU. En contraste, está el Banco Comunitario B, que tiene como único apoyo al Comité Promejoras del barrio Atucucho, por lo tanto, su alcance económico y territorial se encuentra efectivamente limitado a la escasez de recursos con que cuenta, dado que ellos provienen en su totalidad de la autogestión de sus socios.

Ahora bien, los elementos indicados se enmarcan en la concepción de las finanzas populares y solidarias, cuyos principios (ayuda mutua, solidaridad, autogestión, participación democrática, entre otros) difieren de la banca convencional. Subordinados a estos principios se han reconocido tres dimensiones: capital social, orientación hacia el desarrollo local e integración, que unificando al ser humano como fin de las acciones impulsadas por las organizaciones, se puede pensar en lineamientos para la construcción de un modelo de gestión dirigido a la banca comunal en el Ecuador que permita su sostenibilidad integral. En este trabajo se ha dado unos primeros pasos para la construcción de dicho modelo.

\section{Referencias}

Aktouf, O. (2003). La administración: entre la tradición y la renovación. Cali, Colombia: Universidad del Valle.

Bonilla, A. y Rodríguez, P. (1997). Capítulo 2: métodos cuantitativos y cualitativos y capítulo 3: Más allá del dilema de los métodos. Más allá del dilema de los métodos. La investigación en ciencias sociales, (pp. 77-115). Bogotá: Norma. 
Código Orgánico Monetario y Financiero. (12 de septiembre de 2014). Publicado en Registro Oficial n. ${ }^{\circ} 332$. Ecuador.

Constitución de la República del Ecuador. (20 de octubre de 2008). Publicado en Registro Oficial n. ${ }^{\circ} 449$. Ecuador.

Coraggio, J. L. (Noviembre, 2013). Las políticas públicas participativas: ¿obstáculo o requisito para el desarrollo local? Ponencia presentada en el panel "Construcción de poder político y gestión pública participativa en el ámbito local”, del II Seminario Nacional "Fortaleciendo la relación Estado-Sociedad Civil para el Desarrollo local". Buenos Aires, Argentina: CENOG-CEDES-UNGS.

Durston, J. (2003). Capital social: parte del problema, parte de la solución, su papel en la persistencia y en la superación de la pobreza en América Latina y el Caribe. En R. Atria y M. Siles (Comp.), Capital social y reducción de la pobreza en América Latina y el Caribe: en busca de un nuevo paradigma (pp. 147-202). Santiago de Chile: Universidad del Estado de Michigan.

Hammersley, M. y Atkinson, P. (2009). ¿Qué es la etnografia? Barcelona: Paidós.

Hernández, R., Fernández, G. y Baptista, M. (2010). Metodología de la investigación. México: McGraw-Hill / Interamericana Editores, S. A. de C. V.

Hintze, S. (2004). Capital social y estrategias de supervivencia. Reflexiones sobre el "capital social de los pobres". En C. Danani (Comp.), Políticas sociales y economía social: debates fundamentales (pp. 143-166). Buenos Aires, Argentina: UNGS-Fundación OSDEAltamira, Colección de Lecturas sobre Economía Social.

Laville, J. L. (1993). L'économie solidaire. Une perspective internationale. París, Francia: Desclée de Brouwer.

Ley Orgánica de Economía Popular y Solidaria y del Sector Financiero Popular y Solidario. (10 de mayo de 2012). Publicado en Registro Oficial n. ${ }^{\circ} 444$. Ecuador.

López, P. y Mariño, A. (2010). Hacia una evolución en el campo del conocimiento de la disciplina administrativa: de la administración de empresas a la gestión de organizaciones. Red de Revistas Científicas de América Latina, el Caribe, España y Portugal, 19(2), 75-95. Recuperado de http://www.redalyc.org/articulo.oa?id=90920053004

Mansell, C. (1995). Las finanzas populares en México: el redescubrimiento de un sistema financiero olvidado. México: Instituto Tecnológico Autónomo de México.

Miño, W. (2013). Historia del cooperativismo en Ecuador. Quito: Ministerio de Coordinación de Política Económica. 
Muñoz, R. (2006). Alcance de las microfinanzas para el desarrollo local. Microcrédito en el conurbano bonaerense: un análisis de casos. (Tesis de maestría en Economía Social). Buenos Aires, Argentina: Universidad de General Sarmiento.

Muñoz, R. (2013). Finanzas Solidarias. En J. Coraggio (Ed.). Diccionario de la otra Economía (pp. 217-225). Buenos Aires, Argentina: Universidad Nacional de General Sarmiento.

Ortega, C. (2008). Finanzas populares y migración: tejiendo la red para el desarrollo local. Quito: Red de estructuras financieras locales alternativas (REFLA), Fundación Codespa, Fondo Ecuatoriano Populorum Progressio (FEPP).

Orrego, C. y Arboleda, O. (2011). Las organizaciones de economía solidaria: un modelo de gestión innovador. Cuadernos de Administración, 21(34), 97-110. doi:10.25100/cdea. v2 1 i3 4.217 .

Pardo, L., Serrano, R. y Jaramillo, G. (2006). Introducción y diseño metodológico. En L. Pardo (Dir.), Estado del arte de la economía solidaria en Bogotá (pp. 13-24). Bogotá, Colombia: Universidad Cooperativa de Colombia; Universidad Colegio Mayor de Cundinamarca.

Peixoto, P. (2004). Autogestión. En A. Cattani (Comp.), La otra economía (pp. 39-46). Buenos Aires, Argentina: Altamira.

Ragin, C. (1994). La construcción de la investigación social. Introducción a los métodos y su diversidad. Bogotá, Colombia: Siglo del Hombre.

Razeto, L. (2001). Las finanzas sociales, una alternativa de desarrollo en el marco de la economía solidaria. Conferencia dictada en el Foro sobre Finanzas Sociales como Alternativa de Desarrollo Social. México.

Razeto, L. (2010). ¿Qué es la economía solidaria? Papeles de relaciones ecosociales y cambio social, 110, 47-52. Recuperado de http://www.luisrazeto.net/content/ $\% \mathrm{C} 2 \% \mathrm{BFqu} \%$ C3\%A9-es-la-econom $\%$ C3\%AD-solidaria

Rosanvallon, P. (1979). La autogestión. Madrid, España: Fundamentos.

Sevilla, M. T. (2006). Las microfinanzas como una alternativa de desarrollo económico, la experiencia de finca internacional en el Ecuador. (Tesis de maestría en Relaciones Internacionales, mención Economía y Finanzas). Quito, Ecuador: Universidad Andina Simón Bolívar.

Superintendencia de Economía Popular y Solidaria. (2015). Rendición de cuentas 2014. Quito: SEPS. 
Revista CIFE / ISSN: 0124-3551 e-ISSN: 2248-4914 / Bogotá-Colombia / Vol. 20 N.o 32 / enero-junio 2018 / pp. 79 -102

Vuotto, M. y Fardelli, C. (2012). Gobernanza y gestión de las organizaciones de la economía social. Documento de trabajo del Centro de Estudios de Sociología del Trabajo, (79). Buenos Aires, Argentina: FCE-UBA.

Westley, G. (2003). Relato de cuatro programas de Banca Comunal: mejores prácticas en América Latina. Banco Interamericano de Desarrollo: Washington, D. C. 